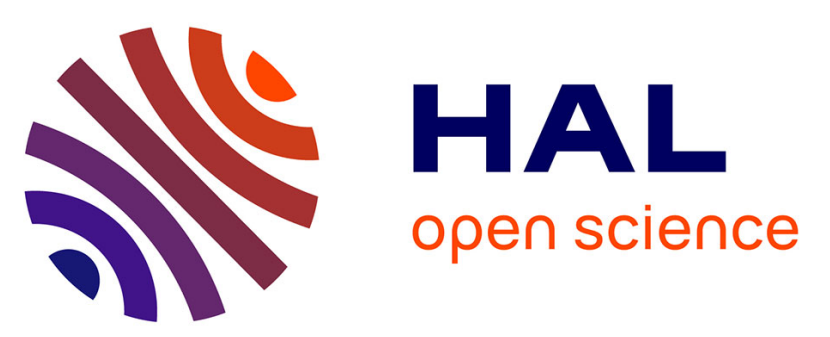

\title{
Evidence of cross-transfer of maternal antibodies through allosuckling in a mammal: potential importance for behavioral ecology
}

Romain R. Garnier, Sylvain S. Gandon, Yannick Y. Chaval, Nathalie N. Charbonnel, Thierry T. Boulinier

\section{To cite this version:}

Romain R. Garnier, Sylvain S. Gandon, Yannick Y. Chaval, Nathalie N. Charbonnel, Thierry T. Boulinier. Evidence of cross-transfer of maternal antibodies through allosuckling in a mammal: potential importance for behavioral ecology. Mammalian Biology: Zeitschrift für Säugetierkunde, 2013, 78 (5), pp.361-364. 10.1016/j.mambio.2012.11.004 . hal-00939800

\section{HAL Id: hal-00939800 https://hal.science/hal-00939800}

Submitted on 29 May 2020

HAL is a multi-disciplinary open access archive for the deposit and dissemination of scientific research documents, whether they are published or not. The documents may come from teaching and research institutions in France or abroad, or from public or private research centers.
L'archive ouverte pluridisciplinaire HAL, est destinée au dépôt et à la diffusion de documents scientifiques de niveau recherche, publiés ou non, émanant des établissements d'enseignement et de recherche français ou étrangers, des laboratoires publics ou privés. 


\title{
Short Communication
}

\section{Evidence of cross-transfer of maternal antibodies through allosuckling in a mammal: Potential importance for behavioral ecology}

\author{
Romain Garnier ${ }^{\mathrm{a}, \mathrm{b}, *}$, Sylvain Gandon ${ }^{\mathrm{a}}$, Yannick Chaval ${ }^{\mathrm{c}}$, Nathalie Charbonnel ${ }^{\mathrm{c}}$, Thierry Boulinier ${ }^{\mathrm{a}}$ \\ a Centre d'Ecologie Fonctionnelle et Evolutive, UMR CNRS 5175, Montpellier, France \\ ${ }^{\mathrm{b}}$ Department of Ecology and Evolutionary Biology, Princeton University, NJ 08544, USA \\ ' INRA, UMR CBGP (INRA/IRD/Cirad/Montpellier SupAgro), Campus international de Baillarguet, CS 30016, F-34988 Montferrier-sur-Lez Cedex, France
}

\section{A R T I C L E I N F O}

\section{Article history:}

Received 24 September 2012

Accepted 23 November 2012

\section{Keywords:}

Meriones unguiculatus

Mongolian gerbil

Ecological immunology

Host-parasite interactions

Transfer of maternal antibodies

Transgenerational vaccination design

\begin{abstract}
A B S T R A C T
The transfer of maternal antibodies is a critical mechanism for the early life survival of vertebrate newborns. In mammals, passive transfer of immune compounds can occur prenatally through the placenta and postnatally through the consumption of colostrum and milk. In social mammals, it has been hypothesized that allosuckling may be a way for pups to broaden and strengthen their passive access to antibodies after birth, but empirical evidence for this mechanism is still lacking. In order to investigate the potential for the occurrence of a cross-transfer of antibodies between pups exposed to several females, we bred in a common environment groups of two females Mongolian gerbils (Meriones unguiculatus), each previously injected with a different vaccine. Here we report the dynamics of passively acquired specific antibodies in the serum of newborns, showing that pups acquired antibodies from both females of a group. Our result provides the first experimental evidence of a cross-transfer between litters of passively acquired antibodies. We discuss how such evidence opens perspectives for exploring the potential importance of horizontal transfer of immunity in natural host-parasite systems and how this could be used as a tool to answer important behavioral ecology questions.
\end{abstract}

(C) 2012 Deutsche Gesellschaft für Säugetierkunde. Published by Elsevier GmbH. All rights reserved.
Environmental conditions encountered by a newborn during early life are important for its fitness later in life (Lindström 1999). Parasites, in particular, represent a major pressure on the population dynamics and evolution of their host species (Grenfell and Dobson 1995; Tompkins et al. 2002). The effect of parasites may potentially be even stronger in young vertebrates whose immune response is not completely functional at birth (Frank 2002). In vertebrates, mothers have the ability to provide the newborn with a protection critical for early life survival (Boulinier and Staszewski 2008; Grindstaff et al. 2003) by transferring some specific molecules produced as part of the acquired immune response, the antibodies (also termed immunoglobulins [Ig]; Brambell 1970). In mammals, this transfer occurs through the placenta before birth and/or via the colostrum and the milk after birth (Baintner 2007). The amount of Igs transferred through the placenta is determined by the anatomical structure of the placenta (Chucri et al. 2010), and in particular by variations in the number of tissue layers between maternal and fetal bloods. Differences in Ig subtypes are also important to consider as only immunoglobulin G (IgG) can reach the newborns bloodstream (Pastoret 1998). Similarly,

\footnotetext{
* Corresponding author at: Department of Ecology and Evolutionary Biology, Princeton University, NJ 08544, USA. Tel.: +1 6092589830.

E-mail address: romaing@princeton.edu (R. Garnier).
}

postnatal absorption of antibodies by newborns also reveals variations across mammalian species. For instance, in artiodactyls, no placental transfer of Igs is possible and colostrum absorption is critical for early life survival (Halliday 1978). In contrast, placental transfer seems to be the dominant route for Igs transfer in primates while Igs in the colostrum and the milk may mostly play a role in the local protection of the gut (Sadeharju et al. 2007). In rodents, both prenatal and postnatal absorption of antibodies appear to be important factors to ensure the survival of the newborn (Gustafsson et al. 1994).

How newborns gain access to colostrum and milk may thus be important in terms of passive transfer of immunity in many mammalian species. An interesting way for newborns to get milk is through allosuckling, when young individuals feed from a different female than their biological mother. Allonursing is indeed widely reported in mammals (Packer et al. 1992; Roulin 2002) and offspring could gain important immunological benefits by acquiring antibodies from various lactating females (immunological function of allosuckling hypothesis; Roulin and Heeb 1999). The potential for an immunological function of allosuckling has been suggested through the efficient transfer of antibodies from a foster mother to her non-biological offspring (e.g. Gustafsson et al. 1994; Halliday 1955). However, adoption in the laboratory does not reflect conditions encountered normally in social groups. In the wild, mothers and newborns are exposed to biological and foster mothers/pups 
at the same time. Mothers may thus choose which pups to suckle and pups may in turn choose from which females to get milk.

In order to investigate the potential for the occurrence of a cross-transfer of antibodies, we focused on a social mammal, the Mongolian gerbil (Meriones unguiculatus). In the wild, this species usually forms groups of one breeding pair associated with a number of subordinates. In the lab however, they can breed successfully in groups, with several females giving birth together (French 1994). Two groups of 12 "specific pathogen free" females (obtained from Janvier, Le Genet-St-Isle, France) were vaccinated twice at 8 and 12 weeks of age respectively against influenza $(0.1 \mathrm{~mL}$, intramuscular injection; Gripovac, Merial, France) or Borrelia burgdorferi $(0.1 \mathrm{~mL}$, subcutaneous injection; Merilym, Merial, France). Antibodies specific of Borrelia (females vaccinated against influenza) or specific of influenza (females vaccinated against Borrelia) remained at undetectable levels throughout the study.

After the booster vaccination, each female was housed during 2 weeks with a male. To prevent direct initial contact and limit aggression, we split the cages with transparent Plexiglas walls (drilled with holes of approximately $1 \mathrm{~cm}$ ). We then switched individuals between each side of the separation everyday during a week to get them used to each other. At the end of the week, the separation was opened and contact between the male and the female was rendered possible. When aggressive interactions among adults were nevertheless recorded, individuals were immediately separated. The same procedure was repeated to match females by pairs based on their vaccination status (one female vaccinated against influenza and the other against Borrelia). The females were subsequently housed together without the males. Pups were thus born in an environment mimicking a natural social system and expected to gain access to the milk of both females and to display detectable levels for both antigens.

At birth, newborns were marked subcutaneously with an individual combination of tattoo ink dots. At 3 weeks of age, before the first marking faded, an additional numbered ear tag (Monel 10051, National Band \& Tag Co., Newport, KY, USA) was used to ensure a long lasting individual marking of individuals. The same ear tags were also used for the marking of females throughout the experiment. To assess passive antibody acquisition, blood was regularly obtained from the newborns during the rearing period. At day 1 (i.e., within $24 \mathrm{~h}$ after birth, as cages were checked every day) and day 8 , a blood sample $(20-30 \mu \mathrm{L})$ was obtained by cardiac puncture using an insulin syringe with $30 \mathrm{G}$ needle. After eyes had opened, blood sampling consisted of a puncture each week (starting day 19 , and up to day 48 ) in the retro-orbital venal sinus with a heparinized capillary tube $(75 \mu \mathrm{L})$, alternatively from the left and right eye. Blood was then stored in dry tubes and centrifugated within an hour. The plasma was collected and kept frozen at $-20^{\circ} \mathrm{C}$ pending analyses. This sampling protocol was chosen to follow the newborns for a sufficiently long period after weaning (between 21 and 30 day; Norris and Adams 1972).

Antibody levels in newborns were measured using specific commercial Enzyme Linked Immuno-Sorbent Assays (ELISA). An indirect ELISA kit was used for influenza (ID Screen Antibody Influenza A Competition, ID Vet, Montpellier, France). The percentage of inhibition (PI) relative to a negative control was used as a measure of antibody level. High PI values indicate high plasma concentrations of specific antibodies against influenza. A direct ELISA kit was used for Borrelia analyses (Borrelia IgG + VlsE ELISA, IBL International GMBH, Hamburg, Germany). As this kit is designed for humans, we replaced the secondary antibody by a peroxidase conjugated rabbit anti-gerbil IgG (Immunology Consultants Laboratory, Portland, OR, USA). Optical density (OD) was used as a measure of antibody levels in the newborns and high OD values reflected high serum levels of Borrelia specific antibodies. Analyses were run once for each sample due to the limited amount of serum available and were limited to the 4 pups that reached adulthood as complete dynamics over the rearing period were required to assess the dynamics of the passive transfer of antibodies.

The present study complies with the guidelines set in the Guide for the care and use of laboratory animals (National Research Council 2011) and the protocol has been approved by the Animal Care and Use Committee - Languedoc Roussillon (project number CEEA-LR-1003). In addition, because of the repeated sampling of newborns required by the protocol, we chose not to include any control group in order to minimize the number of animals used.

Despite preventive measures to limit agonistic interactions, females showed high levels of aggressiveness toward males. In addition, high rates of cannibalism of females on pups occurred rapidly after birth. The latter made it impossible to keep track of the exact number of births over the 12 female pairs set up. For only one pair of females, seven pups were found alive at day 1 . Three of these newborns died during their first week, but the two females were able to raise the four remaining pups to adulthood. At birth, three of those four pups had high anti-Borrelia antibody levels while the remaining one had a much lower level (Fig. 1). As IgG against Borrelia can be transmitted through the placenta in rodents (Morshed et al. 1993), this result suggests that those three pups were born to the Borrelia vaccinated mother. The female vaccinated against influenza likely gave birth to the remaining one. Anti-Borrelia antibody levels showed a steep increase during the first week of age which can be explained by the acquisition of maternal antibodies from the milk. All individuals reached very high levels by 8 days of age. The antibody levels remained relatively stable between 8 and 19 days of age, which is expected as newborns fed on milk during this period. Afterwards, antibody levels decreased rapidly and reached non-detectable levels by 40 days of age. The dynamics was similar for anti-influenza antibodies throughout the rearing period of newborns (Fig. 2). However, at birth, all individuals had no detectable antibodies indicating that antibodies against the nucleoprotein of influenza viruses may not be transmitted through the placenta.

All newborns displayed at some point during the rearing period detectable antibody levels specifically directed against both Borrelia and influenza. Although there was no control group of offspring raised by unvaccinated mothers, the decay of antibody levels following weaning is not consistent with a stimulation of the immune system of the newborns. It rather fits the dynamics expected if the newborns passively acquired antibodies from both females. This result demonstrates the efficiency of allosuckling as a source of antibodies in newborns and provides evidence for a potential immunological function of allosuckling. The transmission of antibodies from a mother to foster offspring has been described before but this is the first time that cross-transfer of antibodies has been reported in a social context, when females can choose which young to suckle and when newborns can choose from which female to suck.

A number of challenges related to the breeding of gerbils have reduced the sample size in the present study. A way to reduce aggressiveness problems could be to rear non-sexually mature individuals in groups of one male and two females. Because the social group would not have been modified recently before the females give birth, lower levels of infanticide could be expected (e.g. Elwood 1991). Another possibility is to pair females only after the pups were born. In this latter case, the identity of the mother of the pups would be known and one could thus avoid sampling newborns in the very few days following birth. However, such a design would limit the access of pups to the colostrum of non-biological mothers and in turn may modify the dynamics of acquisition of passive antibodies by the newborns.

The rapid decay of antibody levels starting after 20 days of age is associated with weaning, which usually occurs between 21 and 


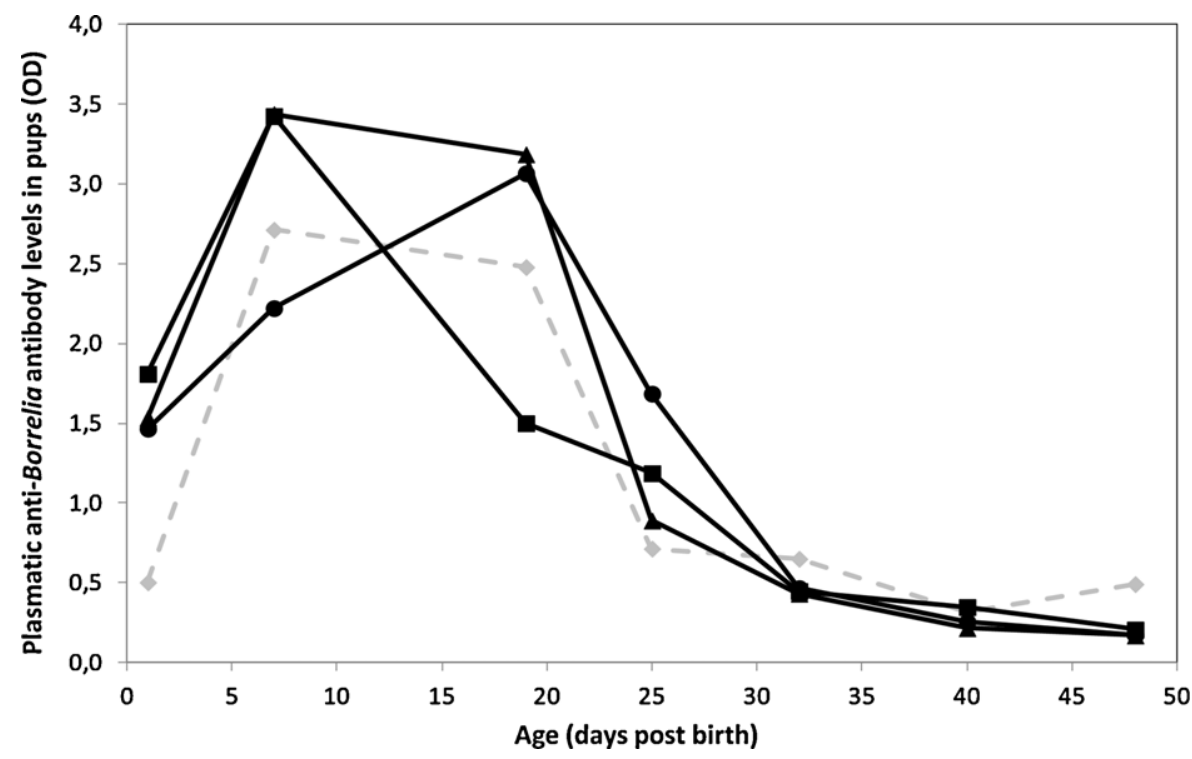

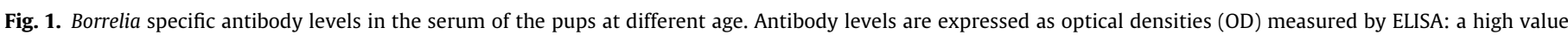

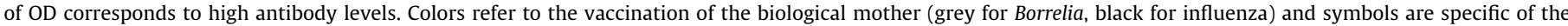

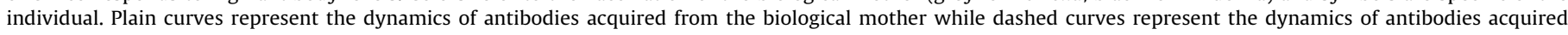
through allosuckling.

30 days in Mongolian gerbils (Norris and Adams 1972). At that time, newborns stop feeding on milk and do not acquire passive immunity from their mothers. The transfer of antibodies from the intestinal lumen to the bloodstream of the newborn indeed relies on a receptor, the neonatal Fc receptor (FcRn) which has in mice been shown to be expressed in the gut only during the neonatal period (Roopenian and Akilesh 2007). If and how this receptor is expressed in the intestine of newborn gerbils is unknown but it probably influences the acquisition of passive antibodies.

Our result suggests that newborns may receive antibodies from several lactating females of a social group. However, how newborns will have access to antibodies is likely to vary with the synchrony of births within groups. Offspring from the first litter, usually born to the dominant female, may for instance be able to broaden and strengthen their repertoire of antibodies with the colostrum of foster mothers. Conversely, pups born later to subordinate females would only gain access to a limited amount of antibodies from the dominant female's milk. The existence of an efficient cross-transfer of antibodies may also contribute to the decision of dominant females to allow subordinate breeding. In some social mammals, such as banded mongooses (Mungos mungo), subordinate females can also be forced out of the group during the course of the gestation (Cant et al. 2010; Gilchrist 2006). Excluded females can subsequently be reintegrated in the group after aborting. Should this abortion occur late in gestation, it has the potential to result in spontaneous lactation which may further reduce the amount of maternal care required from the dominant female. In addition, subordinate females may experience a rather different parasitic

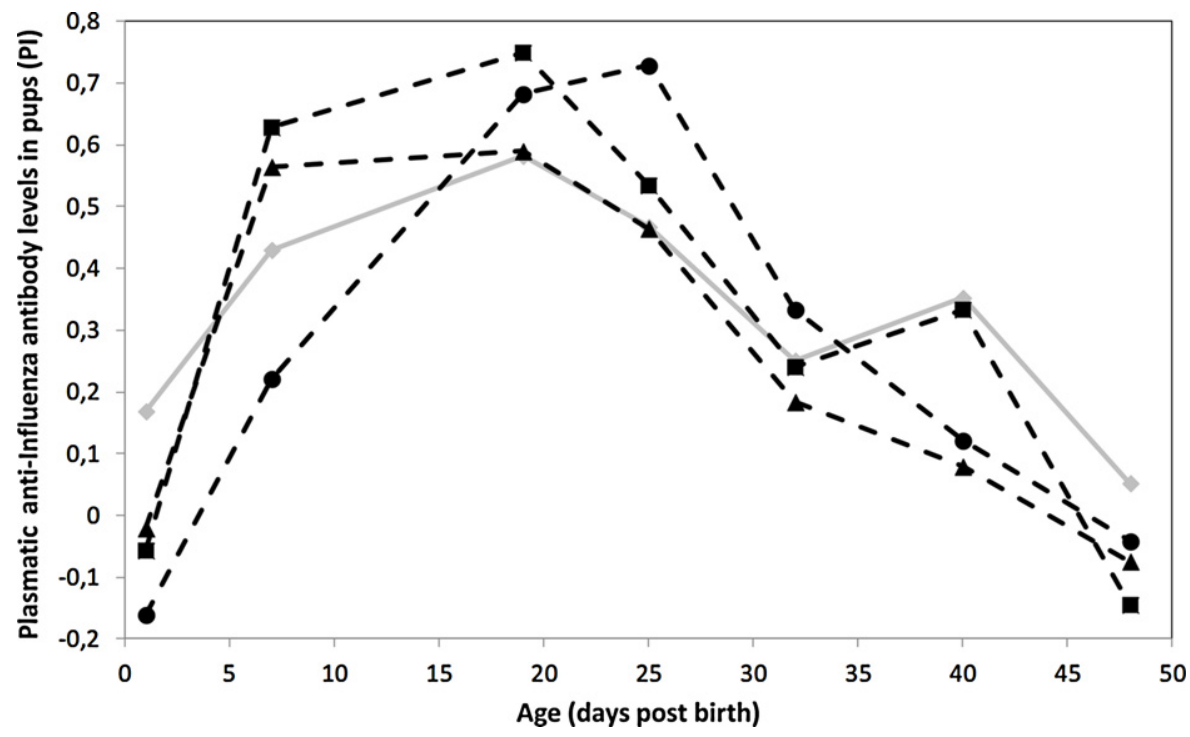

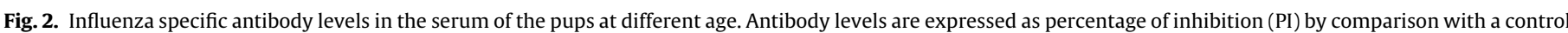

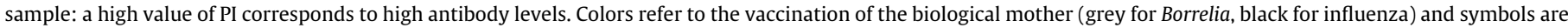

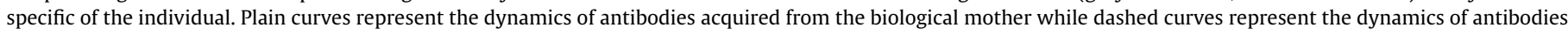
acquired through allosuckling. 
environment during the course of exclusion and broaden the repertoire of the pups of the dominant female through cross-transfer of antibodies.

The use of vaccines (Staszewski and Boulinier 2004) as individual markers of females could allow the exploration of the cross-transfer of antibodies in the wild. If each female from a social group receives a different vaccine, antibodies against each vaccine could be searched for in newborns and used to assess the transfer of antibodies through allosuckling. The choice of the vaccines should be made carefully not only to ensure safety for the vaccinated individuals but also the availability of accurate ELISA techniques to measure specific antibody levels in the pups. A single blood sample of the newborn at a carefully chosen time would be sufficient to obtain evidence for the cross-transfer of antibodies. Finer resolution antibody dynamics could allow for the exploration of the effect of birth synchrony within groups. Social mammals such as meerkats (Clutton-Brock et al. 2001), banded mongooses (Cant 2000) or rodents (e.g. the Alpine marmot, Cohas and Allainé 2009) for which long-term monitoring programs are already implemented might prove particularly suitable for such studies.

\section{Acknowledgements}

The authors thank Audrey Arnal, Carine Brouat, Philippe Perret, Aurore Ponchon and Anne Xuereb for discussions and help at various stages of the experiment and two anonymous reviewers for comments on an earlier version of the manuscript. Technical help for the immunological analyses was provided by the PACE. The members of the "Terrain d'Expérience" platform at the CEFE-CNRS played an important role by designing and producing the Plexiglas separations. Financial support for this study came from the Centre National de la Recherche Scientifique (CNRS) and the Agence Nationale de la Recherche (ANR) grants 07 JCJC 0128 "EPICE" to SG and 11 BSV7 003 "EVEMATA" to TB. RG was supported by a PhD fellowship from the French Ministry of Research.

\section{References}

Baintner, K., 2007. Transmission of antibodies from mother to young: evolutionary strategies in a proteolytic environment. Vet. Immunol. Immunopathol. 117, 153-161.

Boulinier, T., Staszewski, V., 2008. Maternal transfer of antibodies: raising immunoecology issues. Trends Ecol. Evol. 23, 282-288.

Brambell, F.W.R., 1970. The Transmission of Passive Immunity from Mother to Young. American Elsevier Publishing Company, New York, USA.

Cant, M., 2000. Social control of reproduction in banded mongooses. Anim. Behav. 59, 147-158.

Cant, M.A., Hodge, S.J., Vell, M.B.V., Gilchrist, J.S., Nichols, H.J., 2010. Reproductive control via eviction (but not the threat of eviction) in banded mongooses. Proc. R. Soc. Lond. B: Biol. Sci. 277, 2219-2226.
Chucri, T.M., Monteiro, J.M., Lima, A.R., Salvadori, M.L.B., Kfoury Jr., J.R., Miglino, M.A., 2010. A review of immune transfer by the placenta. J. Reprod. Immunol. 87, 14-20.

Clutton-Brock, T.H., Brotherton, P.N.M., Russell, A.F., O'Riain, M.J., Gaynor, D., Kansky, R., Griffin, A., Manser, M., Sharpe, L., McIlrath, G.M., Small, T., Moss, A., Monfort S., 2001. Cooperation, control, and concession in meerkat groups. Science 291 $478-481$.

Cohas, A., Allainé, D., 2009. Social structure influences extra-pair paternity in socially monogamous mammals. Biol. Lett. 5, 313-316.

Elwood, R.W., 1991. Ethical implications of studies on infanticide and materna aggression in rodents. Anim. Behav. 42, 841-849.

Frank, S.A., 2002. Immunology and Evolution of Infectious Disease. Princeton University Press, Princeton, NJ, 348 pp.

French, J.A., 1994. Alloparents in the Mongolian gerbil - impact on long-term reproductive performance of breeders and opportunities for independent reproduction. Behav. Ecol. 5, 273-279.

Gilchrist, J.S., 2006. Female eviction, abortion, and infanticide in banded mongooses (Mungos mungo): implications for social control of reproduction and synchronized parturition. Behav. Ecol. 17, 664-669.

Grenfell, B.T., Dobson, A.P., 1995. Ecology of Infectious Diseases in Natural Populations. Cambridge University Press, Cambridge, UK, 521 pp.

Grindstaff, J.L., Brodie III, E.D., Ketterson, E.D., 2003. Immune function across generations: integrating mechanism and evolutionary process in maternal antibody transmission. Proc. R. Soc. Lond. B: Biol. Sci. 270, 2309-2319.

Gustafsson, E., Mattsson, A., Holmdahl, R., Mattsson, R., 1994. Pregnancy in B-Celldeficient mice - postpartum transfer of immunoglobulins prevents neonata runting and death. Biol. Reprod. 51,1173-1180.

Halliday, R., 1955. Prenatal and postnatal transmission of passive immunity to young rats. Proc. R. Soc. Lond. B: Biol. Sci. 144, 427-430.

Halliday, R., 1978. Variation in immunoglobulin transfer from ewes to lambs. Ann. Rech. Vet. 9, 367-374.

Lindström, J., 1999. Early development and fitness in birds and mammals. Trends Ecol. Evol. 14, 343-348.

Morshed, M.G., Yokota, M., Nakazawa, T., Konishi, H., 1993. Transfer of antibody against Borrelia duttonii from mother to young in Ddy mice. Infect. Immun. 61 4147-4152.

National Research Council, 2011. Guide for the Care and Use of Laboratory Animals 8th edition. The National Academies Press, Washington, USA.

Norris, M.L., Adams, C.E., 1972. Mortality form birth to weaning in the Mongolian gerbil Meriones unguiculatus. Lab. Anim. 6, 49-53.

Packer, C., Lewis, S., Pusey, A., 1992. A comparative analysis of non-offspring nursing Anim. Behav. 43, 265-281.

Pastoret, P.P., 1998. Handbook of Vertebrate Immunology. Academic Press Limited London, UK.

Roopenian, D.C., Akilesh, S., 2007. FcRn: the neonatal Fc receptor comes of age. Nat Rev. Immunol. 7, 715-725.

Roulin, A., 2002. Why do lactating females nurse alien offspring? A review of hypotheses and empirical evidence. Anim. Behav. 63, 201-208.

Roulin, A., Heeb, P., 1999. The immunological function of allosuckling. Ecol. Lett. 2, 319-324.

Sadeharju, K., Knip, M., Virtanen, S.M., Savilahti, E., Tauriainen, S., Koskela, P., Åkerblom, H.K., Hyöty, H., Finish TRIGR Study Group, 2007. Maternal antibodies in breast milk protect the child from enterovirus infections. Pediatrics 119 941-946.

Staszewski, V., Boulinier, T., 2004. Vaccination: a way to address questions in behavioral and population ecology? Trends Parasitol. 20, 17-22.

Tompkins, D.M., Dobson, A.P., Arneberg, P., Begon, M.E., Cattadori, I.M., Greenman, J.V., Heesterbeek, J.A.P., Hudson, P.J., Newborn, D., Pugliese, A., Rizzoli, A.P., Rosà, R., Rosso, F., Wilson, K., 2002. Parasites and host population dynamics. In: Hudson, P.J., Rizzoli, A., Grenfell, B.T., Heesterbeek, H., Dobson, A.P. (Eds.), The Ecology of Wildlife Diseases. Oxford University Press, Oxford, UK, pp. 45-62. 